\title{
Linking Hydrogen $\left(\delta^{2} \mathrm{H}\right)$ Isotopes in Feathers and Precipitation: Sources of Variance and Consequences for Assignment to Isoscapes
}

\author{
Keith A. Hobson ${ }^{1 *}$, Steven L. Van Wilgenburg ${ }^{1}$, Leonard I. Wassenaar ${ }^{1}$, Keith Larson ${ }^{2}$
}

1 Environment Canada, Saskatoon, Saskatchewan, Canada, 2 Department of Zoology, Lund University, Lund, Scania, Sweden

\begin{abstract}
Background: Tracking small migrant organisms worldwide has been hampered by technological and recovery limitations and sampling bias inherent in exogenous markers. Naturally occurring stable isotopes of $\mathrm{H}\left(\delta^{2} \mathrm{H}\right)$ in feathers provide an alternative intrinsic marker of animal origin due to the predictable spatial linkage to underlying hydrologically driven flow of $\mathrm{H}$ isotopes into foodwebs. This approach can assess the likelihood that a migrant animal originated from a given location(s) within a continent but requires a robust algorithm linking $\mathrm{H}$ isotopes in tissues of interest to an appropriate hydrological isotopic spatio-temporal pattern, such as weighted-annual rainfall. However, a number of factors contribute to or alter expected isotopic patterns in animals. We present results of an extensive investigation into taxonomic and environmental factors influencing feather $\delta^{2} \mathrm{H}$ patterns across North America.
\end{abstract}

Principal Findings: Stable isotope data were measured from 544 feathers from 40 species and 140 known locations. For $\delta^{2} \mathrm{H}$, the most parsimonious model explaining $83 \%$ of the isotopic variance was found with amount-weighted growing season precipitation $\delta^{2} \mathrm{H}$, foraging substrate and migratory strategy.

Conclusions/Significance: This extensive $\mathrm{H}$ isotopic analysis of known-origin feathers of songbirds in North America and elsewhere reconfirmed the strong coupling between tissue $\delta^{2} \mathrm{H}$ and global hydrologic $\delta^{2} \mathrm{H}$ patterns, and accounting for variance associated with foraging substrate and migratory strategy, can be used in conservation and research for the purpose of assigning birds and other species to their approximate origin.

Citation: Hobson KA, Van Wilgenburg SL, Wassenaar LI, Larson K (2012) Linking Hydrogen $\left(\delta^{2} \mathrm{H}\right)$ Isotopes in Feathers and Precipitation: Sources of Variance and Consequences for Assignment to Isoscapes. PLoS ONE 7(4): e35137. doi:10.1371/journal.pone.0035137

Editor: R. Mark Brigham, University of Regina, Canada

Received January 17, 2012; Accepted March 13, 2012; Published April 11, 2012

Copyright: (C) 2012 Hobson et al. This is an open-access article distributed under the terms of the Creative Commons Attribution License, which permits unrestricted use, distribution, and reproduction in any medium, provided the original author and source are credited.

Funding: The collection and curation of the majority of feathers used in this study and housed at UCLA's Center for Tropical Research was made possible by grants from the Turner Foundation, the Environmental Protection Agency (R827109-01-0 and R 833778), the National Science Foundation (DEB-9726425 and IRCEB- 9977072), the National Science Foundation-National Institute of Health Ecology of Infectious Diseases Program (grant number EF- 0430146), the NIAID CEIRS Center for Rapid Influenza Surveillance and Research (Contract Number: HHSN266200700009C), and the National Institute of Allergy and Infectious Diseases (grant number EID-1R01AI074059-01). Isotope analyses were funded by grants to KAH and LIW from Environment Canada. The funders had no role in study design, data collection and analysis, decision to publish, or preparation of the manuscript.

Competing Interests: The authors have declared that no competing interests exist.

* E-mail: Keith.Hobson@ec.gc.ca

\section{Introduction}

The ability to track organisms through time and space by various means has revolutionized our understanding of key evolutionary processes shaping the life histories of migratory organisms [1]. Understanding the geographical connectivity among various stages of the annual cycle of migrants has tremendous benefits towards implementing effective conservation strategies [2]. Advances in migrant research have largely been due to technological devices, such as light-sensitive geolocators affixed to animals $[3,4]$, and breakthroughs are expected through the use of satellites that can detect and track small VHF transmitters on animals (http://icarusinitiative.org/index.html).

Despite exciting technological advances in the use of attached markers to track ever more and smaller organisms remotely or through recapture, external methods unfortunately remain biased to location of effort and small sample sizes. Conversely, intrinsic, naturally occurring molecular or stable isotope markers of origin are comparatively inexpensive, and are unbiased by the restricted distribution of tagged individuals, hence large samples can be obtained in which every individual can be used to infer origins [57].

Among isotopic markers, stable-hydrogen isotopes in animal tissues, especially feathers of birds $\left(\delta^{2} \mathrm{H}_{\mathrm{f}}\right)$, has proven particularly successful because well-known and predictable continental patterns of hydrogen isotopes in rainfall $\left(\delta^{2} \mathrm{H}_{\mathrm{p}}\right)$ are often closely reflected in tissue $\delta^{2} \mathrm{H}$ values. Isotopic locational information is stored in tissues, particularly those that are metabolically inert following growth (e.g. feathers, hair, claws; [8]). Simply put, tissue $\delta^{2} \mathrm{H}$ values can be compared to hydrogen isotopic patterns (isoscapes) in order to infer origins where tissues were grown. For birds, the assignment of individuals and populations to their region of origin using feather $\delta^{2} \mathrm{H}_{\mathrm{f}}$ isoscapes has proven to be a leading advance in establishing migratory connections, especially for migrant and threatened species in North America [9-13] and Europe [14-16]. 
Since the first studies demonstrating the potential of the $\delta^{2} \mathrm{H}_{\mathrm{f}}$ assignment approach $[8,17]$, advances have been made using GIS and Bayesian statistical techniques to derive probabilistic isotopic regions of animal origins $[13,16,18,19]$. These new approaches propagate all known associated errors from the isotopic analyses to deviations from the $\delta^{2} \mathrm{H}_{\mathrm{p}}$ isoscapes on which they are based [20], and thereby provide a more defensible assessment of probable origin, compared to previous regression-based origin mapping. Increasingly, spatial isotopic data from known origin birds and animals are being used to improve and inform the primary algorithms in probabilistic geographic assignment models (reviewed in [6,21]). Despite ongoing advances, a few authors have doubted the accuracy of the intrinsic marker approach and specifically $\mathrm{H}$ isotopes, pointing to potential sources of error that are either not well understood or were poorly handled in the early assignment methods [22-25]. A significant concern was that fundamental precipitation-based hydrologic patterns of deuterium $\left({ }^{2} \mathrm{H}\right)$, that underpin $\mathrm{H}$ isotopic flow into food webs, is based on long-term averages obtained from a 50-year disparate global record, and that it remains unclear how much interannual differences at any location vary from this long term. Secondly, with ongoing research it became clear that no single global assignment algorithm is appropriate for all species, taxa, or age classes [6] as a number of ecophysiological factors may play a role in $\mathrm{H}$ isotopic discrimination ultimately linking tissue and rainfall [26], and that species-specific $\mathrm{H}$-isotope tissue base maps may be required. These apparent $\mathrm{H}$ isotope difference among animals are ultimately linked to possibly numerous processes affecting the $\mathrm{H}$ isotope budget of individuals, most of which remain poorly understood [27]. For example, adult birds that overlap molt with breeding can experience higher metabolic rates and water loss, and thus may result in higher $\delta^{2} \mathrm{H}_{\mathrm{f}}$ values than their sedentary young [28]. In addition, ecologically dissimilar species may sample foodwebs controlled by different components of the hydrological cycle even in the same general area (e.g. wetlands vs. uplands) and so show different $\delta^{2} \mathrm{H}_{\mathrm{f}}$ values. Further, for some species like carnivores the $\mathrm{H}$ isotopes in their tissues have been shown to be almost completely disconnected from the underpinning spatial $\mathrm{H}$ isotope patterns [29]. While most of these challenges can be overcome by constructing species-specific or ecologically equivalent natal $\mathrm{H}$ isotope tissue basemaps within the timeframe of a study [21], this requires a herculean effort for most species, and access to spatially extensive and remote areas for many Neotropical migrants remains a huge challenge. Thus, efforts to obtain assignments for groups of "like" organisms remains an ongoing area of research.

Hobson and Wassenaar [8] derived the first $\mathrm{H}$ isotope assignment algorithm for insectivorous passerines in North America by sampling adult breeding birds across a latitudinal gradient. They assumed those individuals grew their flight feathers at those sampled locations the year before, but were unable to control for possible natal dispersal into those populations. Other studies, such as [30] established a $\mathrm{H}$ isotope assignment base map or isoscape for several species of raptors in North America. They based their sampling on juvenile birds that were closely associated with sampling locations, but it later became clear that such an isoscape cannot necessarily be used for carnivorous adult raptors [28]. Since these attempts, basemap isoscapes have been constructed for waterfowl [31] and European species [26], but it is still uncertain how generalizeable these feather isoscapes are. This uncertainty remains the single greatest impediment to the broader application of $\mathrm{H}$ isotope techniques to estimate of origins of migratory birds.
Here, we obtained and measured $\mathrm{H}$ isotopes in a large collection of feathers from across North America, which included a new group of songbird individuals that were known with certainty to have grown their feathers at specific sites across contiguous North America. Our objective was to construct the best possible calibrated feather isoscape for passerines and other species in North America and to further quantify what biotic and abiotic factors may influence isotopic patterns across large geographic scales.

\section{Methods}

\section{Ethics statement}

This study was conducted under authority of the Canadian Council for Animal Care as reviewed by the University of Saskatchewan (Permit 20100084). All federal permits for the use of feather material were issued by the Canadian Wildlife Service and the U.S. Fish and Wildlife Service.

\section{Samples}

The majority $(n=434$ of 544$)$ of feathers sampled were outertail feathers (rectrices) of passerines collected during the breeding season at constant-effort mist-netting sites such as MAPS (Monitoring Avian Productivity and Survivorship, [32]) and by other groups across North America. These samples were selected from a collection stored at the Center for Tropical Research (CTR) at University of California Los Angeles (UCLA). Feather samples for analysis were selected from two databases at CTR, one maintained for the study of migratory connectivity related to studies of avian influenza $(\mathrm{N}=56443$; database version: 2009.10.12) and another called "Neotrops" ( $\mathrm{N}=57468$; database version 2009.06.18) used for the study of migratory connectivity generally. We queried these databases to select only individuals that were captured during the breeding season (May to July) and in at least two different years at the same location. This "recapture" criterion was used to identify individuals that breed at a single location. We further restricted feather sample selection to birds in which the prior capture occurred in the year immediately prior to the sample collection, hereby ensuring that we could be certain of the exact location of feather growth. Birds that were captured during their hatching year and then recaptured in subsequent years were eliminated to avoid confounding age effects. The locations of these sampling sites are shown in Fig. 1.

In addition, sampling was restricted to species known to have a complete pre-basic (post-breeding) molt on the breeding grounds [33], namely the annual molt of their flight feathers occurring on the breeding grounds, to avoid potential complication of inadvertently sampling a feather grown the previous years. This careful screening results in some spatial data gaps, thus 60 samples were included from species that are known to occasionally undergo molt-migration or molting during migration and hence away from the breeding grounds; however, data from these samples were carefully examined for outliers. The locations of these sample sites are shown in Figure 1.

In addition to known origin samples obtained from the CTR sample collection, first primary $(\mathrm{P} 1)$ samples were obtained from 91 samples collected at 16 sites in Canada. These included 25 samples from after-second year Ovenbirds (Seiurus auricapilla) for which it was assumed they held the same territory between years. Samples were obtained from 33 recaptured Golden-winged Warblers (Vermivora chrysoptera) from a mark-recapture experiment, and 30 hatching-year Tree Swallows (Tachycineta bicolor) captured near their nesting location. The locations of these sample sites are 


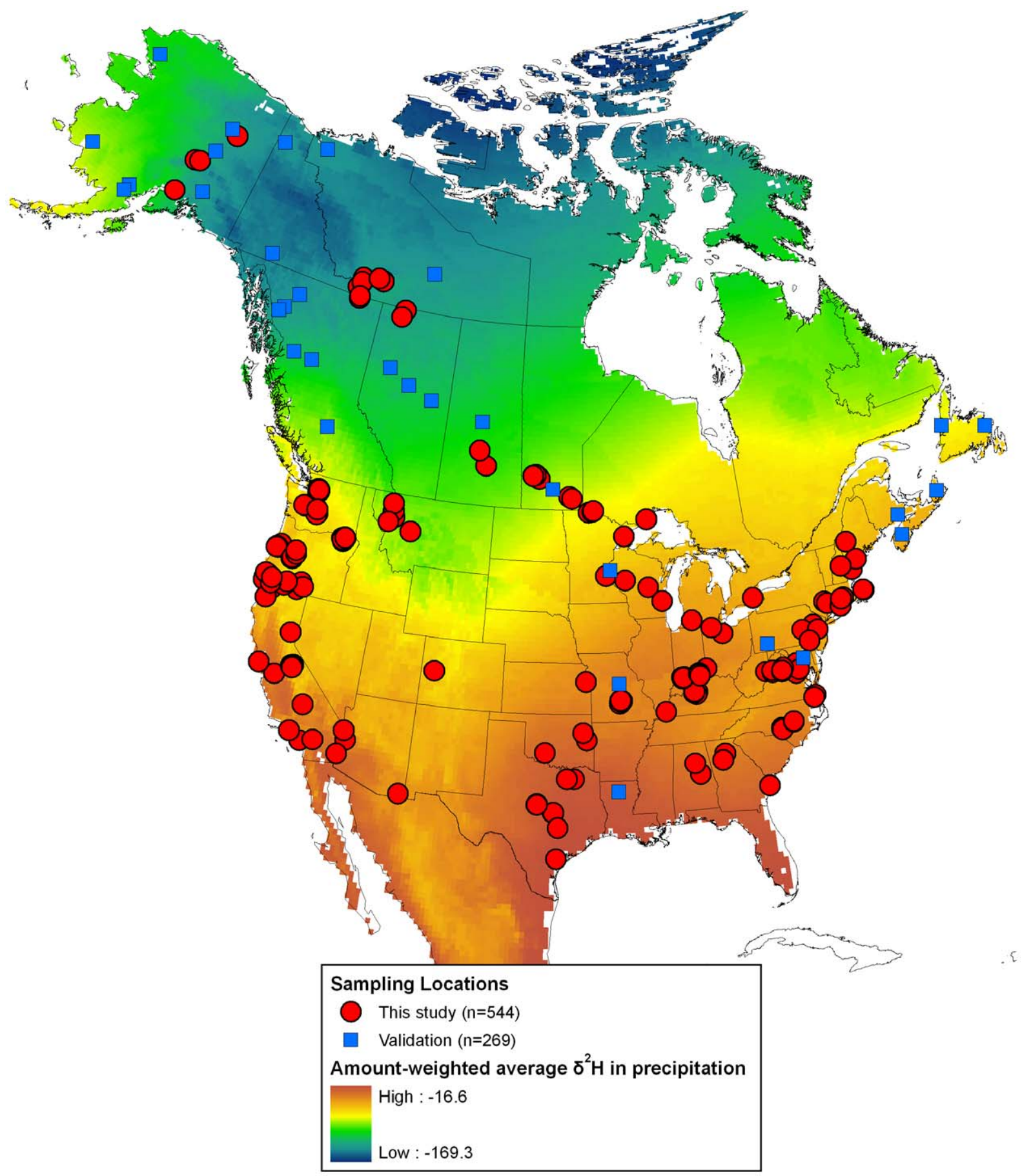

Figure 1. Location of feather sample collection sites and the underlying gradient in amount-weighted average $\delta^{2} \mathrm{H}$ in precipitation. Shown are locations for 544 calibration samples collected for this study, and the location of 269 samples from previously published sources used as model validation samples. Underlying isoscape based on Bowen et al. [20]. doi:10.1371/journal.pone.0035137.g001

included in Figure 1 and a description of the species used are provided in Table $\mathrm{S} 1$.

\section{Stable isotope analyses}

All feathers were cleaned of surface oils in 2:1 chloroform:methanol solvent rinse and prepared for $\delta^{2} \mathrm{H}$ analysis at the Stable Isotope Laboratory of Environment Canada, Saskatoon, Canada. The impact of exchangeable hydrogen was corrected by conducting hydrogen isotope analyses using the comparative equilibration method described by [34] and using three calibrated keratin hydrogen-isotope reference materials. H Isotopic measurements were performed on $\mathrm{H}_{2}$ gas derived from high-temperature $\left(1350^{\circ} \mathrm{C}\right)$ flash pyrolysis of $350 \pm 10 \mathrm{ug}$ feather subsamples from the distal section of feather vane and keratin standards using continuous-flow isotope-ratio mass spectrometry. Measurement of the three keratin laboratory reference materials (CFS, CHS, BWB) 
corrected for linear instrumental drift were both accurate and precise with typical mean $\delta^{2} \mathrm{H} \pm \mathrm{SD}$ values of $-147.4 \pm 0.79 \%$ $(n=5),-187 \pm 0.56 \%(n=5)$ and $-108 \pm 0.33 \%$ o $(n=5)$, respectively. A control keratin reference yielded a 6 -month running SD of $\pm 3.3 \%$ o $(n=76)$. All results are reported for non-exchangeable $\mathrm{H}$ expressed in the typical delta notation, in units of per mil (\%o), and normalized on the Vienna Standard Mean Ocean Water Standard Light Antarctic Precipitation (VSMOW-SLAP) standard scale.

\section{Modeling variation in $\delta^{2} \mathrm{H}_{\mathrm{f}}$}

Numerous studies have demonstrated the causal link between $\delta^{2} \mathrm{H}$ in rainfall and animal tissues, however, we wished to determine if various life history traits influence this relationship. Thus, life history data was obtained from the Avian Life History Information Database (http://www.on.ec.gc.ca/wildlife/ wildspace/project.cfm), or from species accounts in the Birds of North America [35]. Using these data, the species were categorized into 1) foraging guild (insectivore, omnivore), 2) foraging substrate (ground foragers versus species foraging elsewhere (in shrubs, canopy or aerially; hereafter non-ground foragers)), 3) migratory guild (Neotropical migrant, short-distance migrant, resident), and 4) whether the species was associated with an aquatic versus upland habitat. These life history data were used as factors in all subsequent statistical modeling. As we discuss in more detail below, while not exhaustive, our choice of parameters for modeling variation in $\delta^{2} \mathrm{H}_{\mathrm{f}}$ were based on our expectation that trophic position could influence $\delta^{2} \mathrm{H}_{\mathrm{f}}$, that foodwebs associated with the soil-leaf litter interface may be enriched in ${ }^{2} \mathrm{H}$ over the canopy and shrub layers and that migratory strategy is associated with timing of molt and hence period of isotopic integration. Finally, at continental scales, aquatic environments may represent different hydrogen pools available to birds compared to averaged precipitation.

Prior to modeling spatial variation in $\delta^{2} \mathrm{H}$ of feathers, alternative models of $\delta^{2} \mathrm{H}$ in the underpinning precipitation isoscapes were examined. Previous work on North American migratory birds largely focused on precipitation amount-weighted growing season average $\delta^{2} \mathrm{H}$ in precipitation (namely, based on months where the mean daily temperature was $>0{ }^{\circ} \mathrm{C}$; hereafter $\delta^{2} \mathrm{H}_{\mathrm{p}}$ ), and this was included as one estimate of local $\delta^{2} \mathrm{H}$ in precipitation. However, it remains unclear which months of rainfall exert the greatest influence driving $\mathrm{H}$ isotopic flow into primary foodwebs that contribute to avian diet and feather growth. Thus, the relationship between $\delta^{2} \mathrm{H}_{\mathrm{f}}$ and amountweighted average $\delta^{2} \mathrm{H}$ in precipitation for the months of May through July (hereafter $\delta^{2} \mathrm{H}_{\mathrm{pMay}-J u l y}$ ) time period were also examined. Model-based estimates of $\delta^{2} \mathrm{H}_{\mathrm{p}}$ were obtained from the geospatial model provided by [20]. Estimates of $\delta^{2} \mathrm{H}_{\mathrm{pMay}-J u l y}$ were obtained from a geospatial model of $\delta^{2} \mathrm{H}$ in May-July precipitation using IsoMAP [36], using CRU-derived climatic variables [37] to model $\delta^{2} \mathrm{H}$ in precipitation. During the preliminary analysis it was observed that $\delta^{2} \mathrm{H}_{\mathrm{f}}$ was more strongly correlated with $\delta^{2} \mathrm{H}_{\mathrm{p}}($ Pearson $\mathrm{r}=0.88, \mathrm{p}<0.001)$ than $\delta^{2} \mathrm{H}_{\mathrm{pMay}-}$ July $(\mathrm{r}=0.73, \mathrm{p}<0.001)$ thus all subsequent modeling was done using $\delta^{2} \mathrm{H}_{\mathrm{p}}$ as a linear covariate and $\delta^{2} \mathrm{H}_{\mathrm{p} \text { May-July was not }}$ considered further.

General Linear Models (GLM) were used to statistically model variation in $\delta^{2} \mathrm{H}_{\mathrm{f}}$ from a calibration set of 544 known origin birds from across North America (Figure 1). A preliminary model found only two individual outliers, which were removed prior to subsequent modeling. Of the two outliers, one was significantly depleted $(-81.7 \%$ o relative to isoscape predictions, while the other was substantially more enriched $(58.4 \%$ ) than expected. Exami- nation of the data suggest that the depleted sample likely derived from a food web altered by irrigation from the Colorado River (Williamson County, Texas), whereas the enriched sample was from a riparian associated species (MacGillivray's warbler, Oporornis tolmei) sampled near the Umatilla River in Oregon.

Twenty five a priori candidate GLM models were considered, and the most parsimonious model was selected based on $\mathrm{AIC}_{c}$ (Akaike's Information Criterion adjusted for small sample size) and on AIC model weights [38]. With the exception of an intercept only model, the candidate models included $\delta^{2} \mathrm{H}_{\mathrm{p}}$ as the predictor variable; but varied with the inclusion of those factors for foraging guild, foraging substrate, migratory guild, and age class (hatchingyear and second-year birds versus after hatching-year) and interactions up to the second order.

\section{Examination of residual variation}

Residuals from our top model for variation in $\delta^{2} \mathrm{H}_{\mathrm{f}}$ were explored using descriptive statistics and testing for spatial autocorrelation using Moran's index of autocorrelation. Furthermore, residuals from our top model were examined for variation related to body size (wing-length ( $\mathrm{mm}$ ), body mass (grams)), year of feather growth, and climatic departures from long-term averages during the year of feather growth (North Atlantic Oscillation Index (NAO) and multivariate El Niño-Southern Oscillation Index (ENSO)).

\section{Model validation}

We examined how well our top model performed on temporally distinct data from birds of presumed origin from previously published sources [8,31,39]. First, 269 observed $\delta^{2} \mathrm{H}_{\mathrm{f}}$ values were regressed against predicted $\delta^{2} \mathrm{H}_{\mathrm{f}}$ from the top model. In addition, using these same 269 samples, likelihood-based assignment algorithms [40,41] were used to assign individuals to origins. Briefly, the likelihood-based assignments were conducted by using normal probability density functions to assess the likelihood that an observed $\delta^{2} \mathrm{H}_{\mathrm{f}}$ value could have been generated at a given location given the isoscape predicted value for that location and the level of error inherent in the assignment process. The likelihoods were converted to likely (1) versus unlikely (0) origins by selecting areas associated with a threshold probability density value, based on a user specified odds ratio of being correct versus incorrect $[13,41,42]$. We selected odds of $2: 1$ and $3: 1$ odds respectively (to obtain upper 67 and $75 \%$ of cumulative probabilities respectively), and used the standard deviation of our calibration equation residuals as an estimate of error in the likelihood assessment [13,41,42]. The frequency at which individuals were correctly assigned to the region from where they were captured were examined. The observed frequencies of correct versus incorrect classifications were contrasted with the expected frequencies that should occur under the selected odds ratios (i.e. $67 \%$ and $75 \%$ correct for $2: 1$ and 3:1 odds respectively), using a Chi-squared goodness-of-fit test.

\section{Results}

\section{Variation in $\delta^{2} \mathrm{H}_{\mathrm{f}}$}

A strong relationship was observed between $\delta^{2} \mathrm{H}_{\mathrm{f}}$ and $\delta^{2} \mathrm{H}_{\mathrm{p}}$ (Figure 2A). Of 25 candidate models explored to explain variation in $\delta^{2} \mathrm{H}_{\mathrm{f}}$, one model received overwhelming support (Table S2). The most parsimonious model received $99 \%$ of the support based upon model weights, and was separated from the next model by over $10 \mathrm{AIC}_{\mathrm{c}}$ units. The top model included $\delta^{2} \mathrm{H}_{\mathrm{p}}$, migratory guild, foraging substrate and the interaction between migratory guild and foraging substrate as parameters. The resulting model 

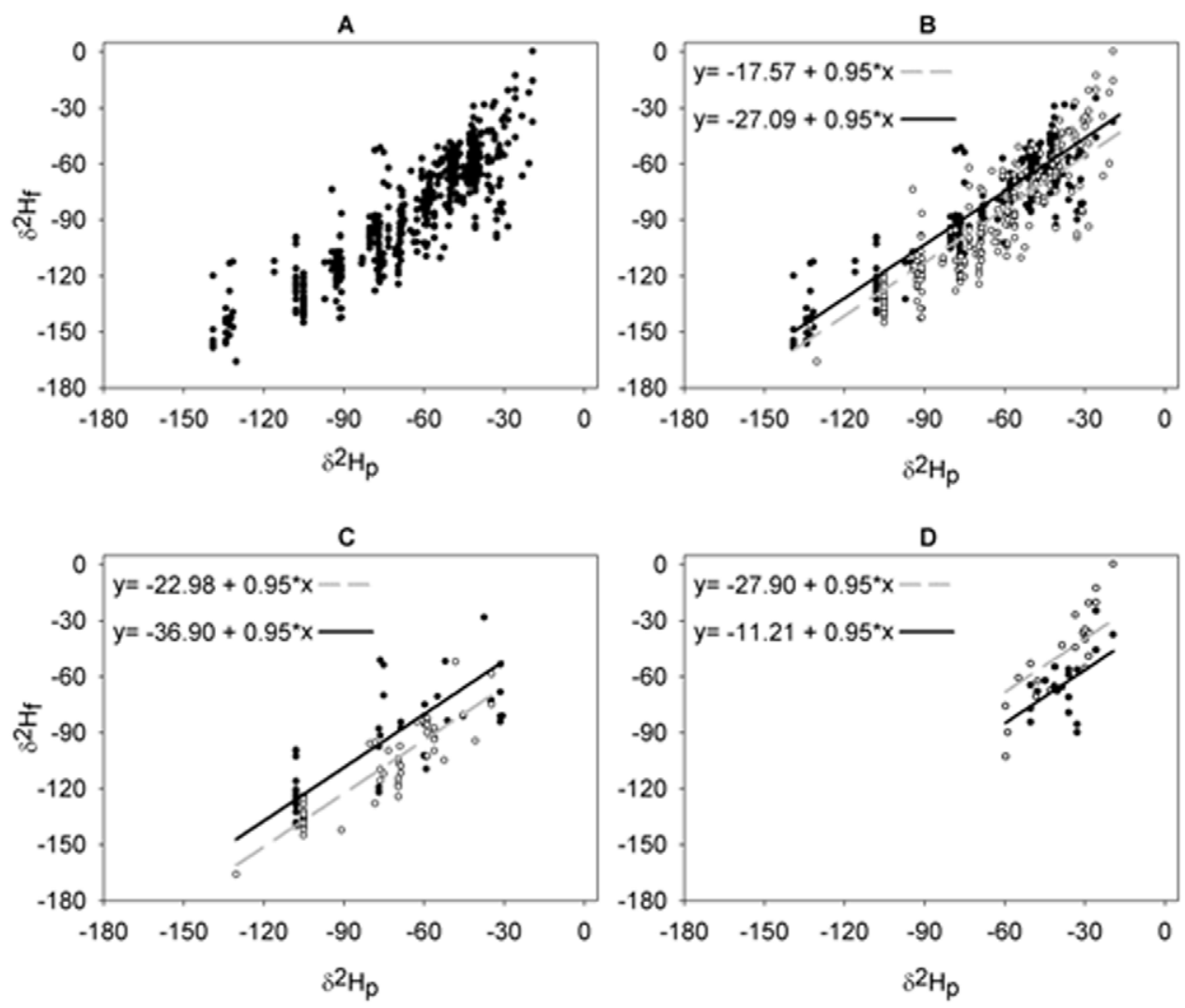

Figure 2. Relationship between $\delta^{2} \mathbf{H}_{\mathbf{f}}$ and isoscape predicted $\delta^{2} \mathbf{H}_{\mathrm{p}}$. A) For 542 model calibration samples, B) for Neotropical migrants, C) for short-distance migrants, and D) for resident species. The relationship between $\delta^{2} \mathrm{H}_{\mathrm{f}}$ and $\delta^{2} \mathrm{H}_{\mathrm{p}}$ was modeled using a linear modeling approach with lines indicating predictions from our best $\mathrm{AIC}_{\mathrm{c}}$ selected model (see methods). Our best model included a factor for whether the species foraged on the ground or elsewhere; thus, the predictive equations and regression line are shown separately for ground foragers (solid lines) and non-ground foragers (dashed lines).

doi:10.1371/journal.pone.0035137.g002

explained a substantial proportion of the variance in $\delta^{2} \mathrm{H}_{\mathrm{f}}$ $\left(\mathrm{F}_{6,535}=436, \mathrm{p}<0.001, \mathrm{r}^{2}=0.83\right)$.

Parameter estimates (Table 1) from the top model were used to derive six predictive equations for estimating $\delta^{2} \mathrm{H}_{\mathrm{f}}$ for birds from a given migratory guild and foraging substrate throughout North America (Figure $2 \mathrm{~B}-\mathrm{D}$ ). Each equation had a common slope of 0.95 (0.02 SE) with $\delta^{2} \mathrm{H}_{\mathrm{p}}$, but different intercepts based upon parameters for migratory guild, foraging substrate and their interaction (Table 1).

Combining parameter estimates for migratory guild, foraging substrate and their interaction (Table 1) showed that non-ground foraging, short-distance migrants had more negative $\delta^{2} \mathrm{H}_{\mathrm{f}}$ values $(\sim-36.9 \%)$, followed by ground foraging resident species ( $\sim-27.9 \%$ o), non-ground foraging Neotropical migrants $(-27.1 \%)$, ground foraging short-distance migrants $(-23.0 \%$ ), ground foraging Neotropical migrants $(-17.6 \%)$, and finally by non-ground foraging resident species $(-11.2 \%$; see Figures $2 \mathrm{~B}-$ D). Thus, with the exception of resident species, migrant ground foragers generally had higher $\delta^{2} \mathrm{H}$ values than migrant species that do not forage on the ground, with an average hydrogen isotopic enrichment of approximately $9.5 \%$ for Neotropical migrants (Figure 2B), and approximately $13.9 \%$ or for short-distance migrants (Figure 2C). The opposite pattern was found for resident species, where it was found that ground foragers were more negative by approximately $16.7 \%$ relative to non-ground foragers.
Table 1. Parameter estimates for the top linear model examining variation in $\delta^{2} \mathrm{H}_{\mathrm{f}}$

\begin{tabular}{llllll}
\hline Parameter & Estimate & SE & t & P \\
\hline Intercept & -17.57 & 1.65 & -10.63 & 0.00 \\
$\delta^{2} \mathrm{H}_{\mathrm{p}}$ & 0.95 & 0.02 & 44.10 & 0.00 \\
Resident dummy $^{\mathrm{a}}$ & -10.33 & 3.15 & -3.27 & 0.00 \\
Short-distance Migrant dummy $^{\mathrm{b}}$ & -5.41 & 2.18 & -2.48 & 0.01 \\
Foraging Substrate dummy $^{\mathrm{c}}$ & -9.52 & 1.32 & -7.20 & 0.00 \\
Resident $^{*}$ Foraging substrate interaction & 26.21 & 4.31 & 6.08 & 0.00 \\
Short-distance Migrant $^{*}$ Foraging substrate & -4.40 & 2.85 & -1.55 & 0.12 \\
interaction & & & & & \\
\hline
\end{tabular}

${ }^{\mathrm{a}} 1=$ Resident, $0=$ Neotropical or Short-distance Migrant.

${ }^{b} 1=$ Short-distance Migrant, $0=$ Neotropical Migrant or Resident

${ }^{c} 1=$ Species foraging in Canopy, shrubs or aerially, $0=$ Ground foraging species. doi:10.1371/journal.pone.0035137.t001

\section{Model validation}

We applied our top model (Table 1) to predict $\delta^{2} \mathrm{H}_{\mathrm{f}}$ for our external validation data set $(n=269)$. Regression of observed versus predicted $\delta^{2} \mathrm{H}_{\mathrm{f}}$ suggested that our model performed reasonably well $\left(\mathrm{F}_{1,267}=835, \mathrm{p}<0.001, \mathrm{r}^{2}=0.76\right)$ at predicting $\delta^{2} \mathrm{H}_{\mathrm{f}}$ for the validation data set (Figure 3 ). However, the parameter 


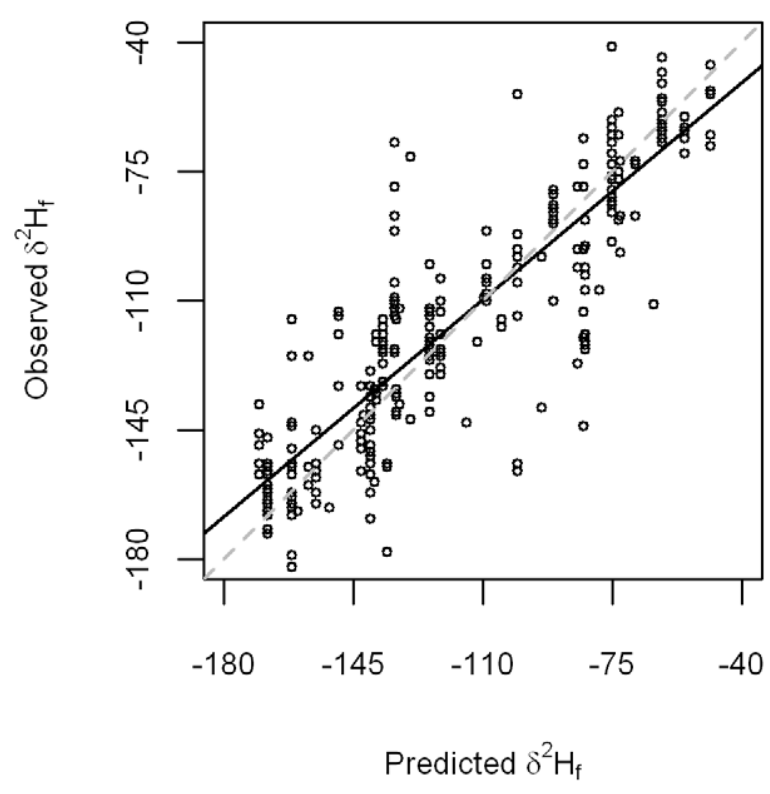

Figure 3. Regression of observed versus model predicted $\delta^{2} \mathbf{H}_{f}$ for $\mathbf{2 6 9}$ samples from previously published sources. Solid line depicts ordinary least squares fit (observed $=-17.38(3.56 \mathrm{SE})+0.84^{*}$ predicted $(0.03 \mathrm{SE}))$, and dashed line is 1:1 correspondence line. doi:10.1371/journal.pone.0035137.g003

estimates from this equation suggested some minor bias, with an intercept of $-17.4 \%$ o $(3.56 \% \mathrm{SE})$, and slope of 0.84 (0.03 SE).

Applying likelihood-based assignments to determine origin for the 269 validation samples resulted in classification accuracies similar to those expected given the specified level of risk. Selecting GIS cells within the isoscape that corresponded to 2:1 odds of correct classification resulted in 172 samples being correctly classified to place of capture, and 97 samples assigned to origins that did not include the place of actual capture. By contrast, the expected frequency of correct to incorrect classifications was 179 to 90 samples, which did not differ from the observed frequencies $\left(\chi^{2}=0.40, \mathrm{df}=1, \mathrm{p}=0.53\right)$. Similarly, at 3:1 odds, the observed frequencies of correct (192) to incorrect (77) classifications did not differ from the expected frequencies of 202 and $67\left(\chi^{2}=0.95\right.$, $\mathrm{df}=1, \mathrm{p}=0.33)$.

\section{Residual variation}

Residuals for the top model were well distributed (Figure 4). The overall model residuals had a standard deviation of $12.9 \%$; however, this varied between migratory guild and foraging substrate (Figure 4). The residuals showed the greatest dispersion was for ground foraging short-distance migrants $(\mathrm{SD}=18.4 \%$, Figure 4A), followed by non-ground foraging Neotropical migrants $(\mathrm{SD}=14.4 \%$, Figure $4 \mathrm{~B})$, ground-foraging Neotropical migrants $(\mathrm{SD}=10.8 \%$, Figure $4 \mathrm{C})$, and non-ground foraging short-distance migrants $(\mathrm{SD}=9.7 \%$, Figure $4 \mathrm{D})$. Model residuals showed no evidence of remaining spatial variation (Moran's I index $=0.03$, $\mathrm{z}=0.34, \mathrm{p}=0.37)$.

In general, the model residuals fit the long-term predictions well, displaying relatively minor inter-annual variation relative to the long-term predictions (Figure 5). Graphical examination of the model residuals against wing length, body mass, and the North Atlantic Oscillation index showed no patterns. By contrast, graphical examination of the residuals against ENSO suggested a potential relationship. Thus, this relationship was tested by fitting two models, an intercept only model and residuals as a function of
ENSO. Of these two candidate models, the intercept only model was somewhat more parsimonious, separated from the ENSO model by only $2.95 \mathrm{AIC}_{c}$ units and receiving $81 \%$ of the support, suggesting there was little support for ENSO related variation in $\delta^{2} \mathrm{H}_{\mathrm{f}}$ in the data.

\section{Discussion}

This was the first study to specifically examine the influence of species natural history on the relationship between $\delta^{2} \mathrm{H}_{\mathrm{p}}$ and $\delta^{2} \mathrm{H}_{\mathrm{f}}$ values at continental scales. Specifically, although there was a straightforward and overwhelming relationship between $\delta^{2} \mathrm{H}_{\mathrm{p}}$ and $\delta^{2} \mathrm{H}_{\mathrm{f}}$ values for North America, it was further identified that foraging guild and substrate were also key factors in this relationship. Recognition of additional ecological factors presented a significant step forward in the ability to use endogenous markers such as stable isotope ratios in feathers to assign geographical origins of passerines in North America and elsewhere.

The influence of foraging substrate on feather $\mathrm{H}$ isotopes, where it was observed that ground foragers generally had comparatively higher $\delta^{2} \mathrm{H}$, was not entirely surprising. Although the $\mathrm{H}$ isotopic differences among foragers appeared to be relatively small (10$36 \%$ ), compared to the global isotopic range in nature of over $250 \%$, these differences are significant enough to cause a substantive disparity in correctly assigning birds to previously established spatial isoscape models.

The precise cause of the $\mathrm{H}$ isotopic differences among migrant and resident foragers remains speculative, but has been previously observed. Hobson et al. [43] found systematic differences in $\delta^{2} \mathrm{H}_{\mathrm{f}}$ values between migrant ground-foraging Ovenbirds and canopyforaging America Redstarts (Setophaga ruticilla) across several sites in the southern boreal of Canada. Similarly [44], found that groundforaging species were enriched in deuterium, over shrub and canopy foragers in a tropical rainforest of Nicaragua. Ground foraging adult Wood Thrush (Hylocichla mustelina) in Georgia were more enriched in ${ }^{2} \mathrm{H}$ than expected from the generalized algorithm used by [45].

The finding that migrant ground-foraging birds were more enriched in ${ }^{2} \mathrm{H}$ than canopy foraging counterparts must be related to local diet or the diet during the period of feather growth or physiological differences between these foraging guilds. Several inter-related possibilities could account for these differences which ultimately result in enrichment in feather ${ }^{2} \mathrm{H}$. One possibility is that soil-level invertebrate prey may be comparatively enriched in ${ }^{2} \mathrm{H}$ compared to shrub and canopy insects due to the evapotranspiration that can occur at the soil-atmosphere interface whereby isotopically light water is preferentially lost to the atmosphere compared to deeper water transmitted to leaves [46]. This would result, all things being equal, to feather ${ }^{2} \mathrm{H}$ enrichment in ground foragers. The effect of evapotranspiration would be expected to be more pronounced in regions of high ambient temperature and/or low humidity. Alternatively, invertebrates used by ground-foraging birds (e.g. beetles, spiders) may simply represent a higher mean trophic level than herbivorous insects associated with the canopy and, if insect $\delta^{2} \mathrm{H}$ correlates positively with trophic level, ground-foraging birds would be enriched in ${ }^{2} \mathrm{H}$ over canopy foraging birds (e.g. [47]).

In contrast, resident ground foragers had lower $\delta^{2} \mathrm{H}_{\mathrm{f}}$ values than resident shrub or canopy foragers. This could be due to growth of feathers earlier in the season whereby ground-based diets are more influenced by winter or spring precipitation that is typically more depleted in ${ }^{2} \mathrm{H}$ [48]. Migratory status is often linked to timing of molt and thus may in turn influence $\delta^{2} \mathrm{H}_{\mathrm{f}}$. Resident species in North America tend to breed earlier than migrants and 
A

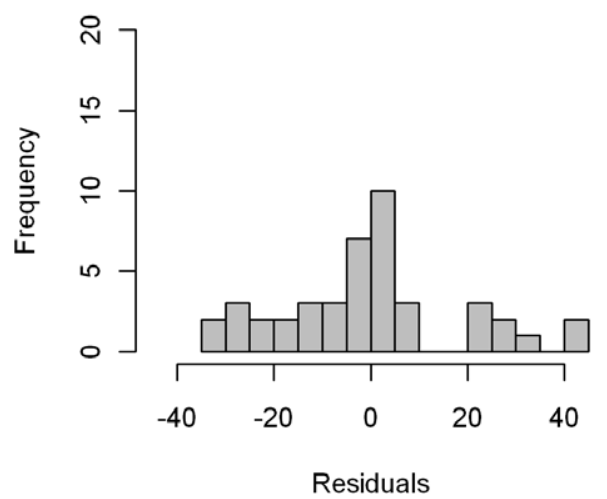

C

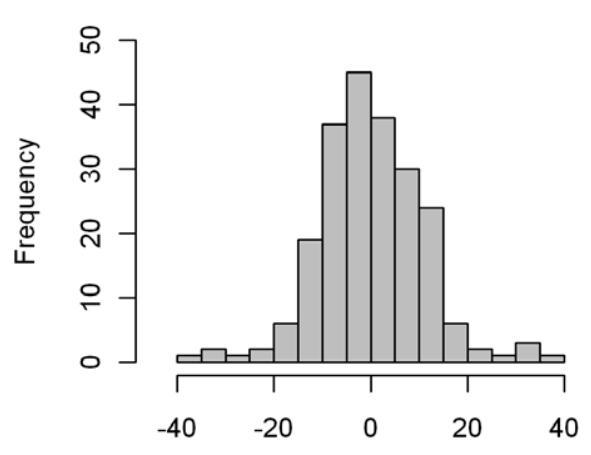

B

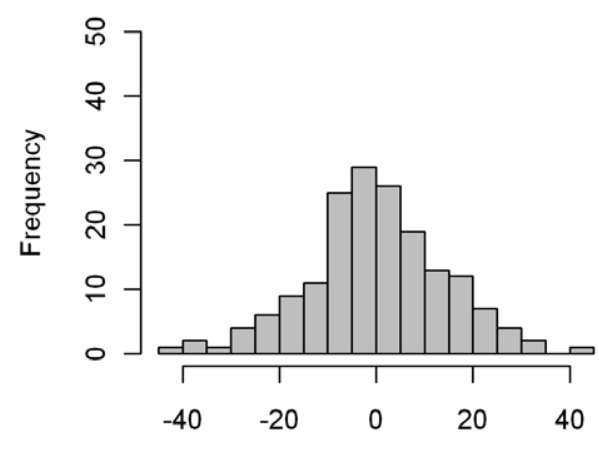

D

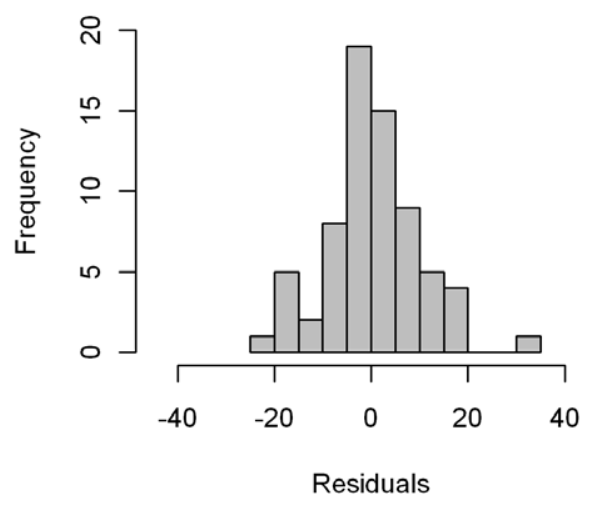

Figure 4. Frequency distribution of residuals from top model. For A) ground foraging short-distance migrants, B) non-ground foraging Neotropical migrants, C) ground foraging Neotropical migrants, and D) non-ground foraging short-distance migrants. Residuals are not shown for resident species.

doi:10.1371/journal.pone.0035137.g004

subsequently molt earlier in the year. This may predispose residents to having lower $\delta^{2} \mathrm{H}_{\mathrm{f}}$ values if winter or spring precipitation made a greater contribution to foodweb $\delta^{2} \mathrm{H}$ values (e.g. earlier plants and insects). Neotropical migrants in North America typically replace flight feathers before migration primarily during July and August. Clearly, possible causal mechanisms underlying the observed differences in $\delta^{2} \mathrm{H}_{\mathrm{f}}$ due to timing of molt and foraging substrate remain speculative and will require more research.

As several authors have indicated, differences in the algorithms linking $\delta^{2} \mathrm{H}_{\mathrm{p}}$ and $\delta^{2} \mathrm{H}_{\mathrm{f}}$ values for North America are not unexpected $[1,19,25,28,30]$. The challenge has been to refine the strong linkage between these factors. This study provides new evidence of the need for further investigation into how factors such as microhabitat characteristics and foraging guild drive variation in the relationship between $\delta^{2} \mathrm{H}_{\mathrm{f}}$ and $\delta^{2} \mathrm{H}_{\mathrm{p}}$. The results of this study are therefore encouraging and underline the fact that the more one can account for isotopic variability in feathers (and other tissues), the greater precision one might expect in assigning birds and other animals to geographic origin using appropriate empirical algorithms.

This study provides renewed and strong support for the enduring relationship between $\delta^{2} \mathrm{H}_{\mathrm{p}}$ and $\delta^{2} \mathrm{H}_{\mathrm{f}}$ values for North America and its application to geographic assignments to origin. Thus, challenges to the $\mathrm{H}$ isotope approach may be unnecessarily alarmist, particularly where North American passerines are concerned [26]. Several authors have argued that the variance associated with this precipitation-tissue $\mathrm{H}$ isotope relationship completely undermines the ability to accurately define origins of migratory birds. For example [24], claimed fundamental limits to the ability to assign migratory wildlife to origin are due to the temporal variation in precipitation isotope ratios as estimated from the Global Network of Isotopes in Precipitation database [24]. However, the clear lack of large systematic departures of the regression residuals from the long-term isoscape predictions (Figure 5), suggested that temporal variations in the GNIP data base may not be an appropriate measure of variance inherent in the assignment process. Indeed, high annual variation in precipitation ${ }^{2} \mathrm{H}$ will be attenuated by averaging effects within the hydrologic cycle (lakes, streams, soil moisture, ground water), the foodweb, and the tendency for $\mathrm{H}$ isotopic variance to average out at higher trophic levels $[26,49]$. Indeed, the results of applying the assignment algorithm to origins to the external validation data set suggested that samples can be assigned to origin at pre-specified levels of accuracy. Thus, in our opinion, the question instead should be how best to handle known sources of variance in both $\delta^{2} \mathrm{H}_{\mathrm{p}}$ and $\delta^{2} \mathrm{H}_{\mathrm{f}}$ when assigning individuals and populations to probability of origin surfaces $[9,19,26,41,42]$. Thus, the distribution of residuals from the robust relationship between $\delta^{2} \mathrm{H}_{\mathrm{f}}$ and $\delta^{2} \mathrm{H}_{\mathrm{p}}$, likely provided a better reflection of the true variance inherent in assignments to origin than variation $\delta^{2} \mathrm{H}$ in precipitation represented in the GNIP isoscape data. 


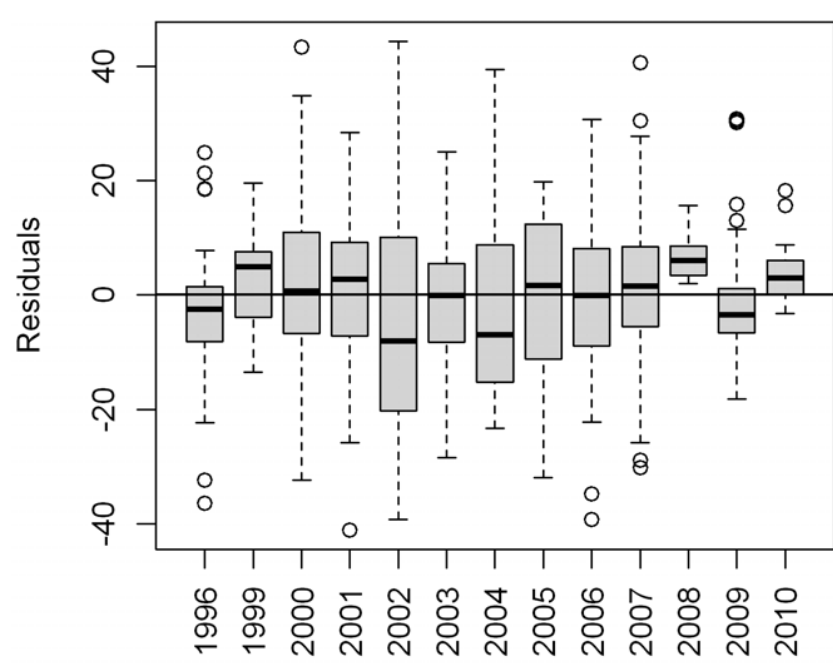

Year of Feather Growth

Figure 5. Boxplot of residuals from the top model for $\delta^{2} \mathbf{H}_{f}$ versus the year in which the feather was grown. Dark solid line represents the median, gray box indicates the range inter-quartile range, whiskers are 1.5 time the inter-quartile range, and dots indicate extreme values. Note: only years with at least ten samples are shown. doi:10.1371/journal.pone.0035137.g005

\section{Supporting Information}

Table S1 List of species sampled for stable hydrogen isotope analysis of feathers and associated categorical factors used in models examining variation in $\delta^{2} \mathrm{H}_{\mathrm{f}}$.

(DOC)

\section{References}

1. Hobson KA, Norris DR (2008) Animal migration: A context for using new techniques and approaches. In: Hobson KA, Wassenaar LI, eds. Tracking animal migration with stable isotopes Academic Press. pp 1-19.

2. Webster MS, Marra PP (2005) The importance of understanding migratory connectivity and seasonal interactions. In: Greenberg R, Marra PP, eds. Birds of two worlds : the ecology and evolution of migration Johns Hopkins University Press. pp 199-221

3. Stutchbury BJM, Tarof SA, Done T, Gow E, Kramer PM, et al. (2009) Tracking long-distance songbird migration by using geolocators. Science 323: 896.

4. Bächler E, Hahn S, Schaub M, Arlettaz R, Jenni L, et al. (2010) Year-Round Tracking of Small Trans-Saharan Migrants Using Light-Level Geolocators. PLoS One. 5(3) e9566. Published online 2010 March 5. doi: 10.1371/ journal.pone.0009566.

5. Hobson KA (2005) Stable isotopes and the determination of avian migratory connectivity and seasonal interactions. Auk 122: 1037-1048.

6. Hobson KA (2008) Applying isotopic methods to tracking animal movements. In: Hobson KA, Wassenaar LI, eds. Tracking animal migration with stable isotopes Academic Press. pp 45-78.

7. Inger R, Bearhop S (2008) Applications of stable isotope analyses to avian ecology. Ibis 150: 447-461.

8. Hobson KA, Wassenaar LI (1997) Linking breeding and wintering grounds of Neotropical migrant songbirds using stable hydrogen isotopic analysis of feathers. Oecologia 109: 142-148.

9. Kelly JF, Atudorei V, Sharp ZD, Finch DM (2002) Insights into Wilson's Warbler migration from analyses of hydrogen stable-isotope ratios. Oecologia 130: $216-221$.

10. Rubenstein DR, Chamberlain CP, Holmes RT, Ayres MP, Waldbauer JR, et al. (2002) Linking breeding and wintering ranges of a migratory songbird using stable isotopes. Science 295: 1062-1065.

11. Dunn EH, Hobson KA, Wassenaar LI, Hussell D, Allen ML (2006) Identification of summer origins of songbirds migrating through southern Canada in Autumn. Avian Conservation Ecology 1: 4. http://www.ace-eco.org/ voll/iss2/art4/.

12. Hobson KA, Aubry Y, Wassenaar LI (2004) Migratory connectivity in Bicknell's Thrush: locating the missing populations using hydrogen isotopes. Condor 106 : 905-909.
Table S2 $\mathrm{AIC}_{\mathrm{c}}$ based model selection statistics for the 25 a priori candidate models used to examine variation in $\delta 2 \mathrm{Hf}$. $K=$ number of parameters, $\mathrm{AIC}_{\mathrm{c}}=$ Akaike's Information Criterion corrected for small sample size, $\Delta \mathrm{AIC} c=$ difference in $\mathrm{AIC}_{\mathrm{c}}$ between model and highest ranked model, and $\omega_{\mathrm{i}}=\mathrm{AIC}$ weight. (DOC)

\section{Acknowledgments}

We thank Thomas Smith and John Pollinger (UCLA) for providing sample databases, coordinating lab visits, space, and providing student assistance to locate samples, and handling permits. Jean Savage handled logistics for lab visit by KWL to UCLA, and Henri Thomassen for provided additional logistical support. Finally Erin Toffelmier at UCLA located samples and prepared all samples for shipment to KAH. Danielle Kaschube at the Institute for Bird Populations verified all data for sampled obtained by the MAPS program partners. Linda Long of the Redwood Sciences Laboratory, USDA Forest Service, provided data validation and location information for LAMNA contributors, and Josée Rousseau at Klamath Bird Observatory who provided additional data validation and location information. We especially thank the thousands of banders at stations across North America for years of banding and collecting feathers. Without the assistance of the staff at UCLA, IBP, LAMNA, KBO, Point Reyes Bird Observatory, the USDA Forest Service, USDA Bureau of Land Management, USDI National Park Service, USDI Fish \& Wildlife Service and so many others we would not have been able to carry out this research. In addition, we thank Erin Bayne and Samuel Haché (University of Alberta), Bob Clark (Environment Canada), and Lauren Bortolloti (University of Alberta) for providing additional Canadian feather samples. Chantel Gryba assisted with sample preparation.

\section{Author Contributions}

Conceived and designed the experiments: KAH KL SLVW LIW. Analyzed the data: SLVW. Wrote the paper: KAH SLVW LIW KL. Stable isotope analysis: LIW.

13. Hobson KA, Wunder MB, Van Wilgenburg SL, Clark RG, Wassenaar LI (2009) A method for investigating population declines of migratory birds using stable isotopes: origins of harvested lesser scaup in North America. PLoS ONE 4(11): e7915. doi:10.1371/journal.pone.0007915.

14. Newton I, Hobson KA, Fox AD, Marquiss M (2006) An investigation into the provenance of Northern Bullfinches Pyrrhula p. pyrrhula found in winter in Scotland and Denmark. Journal of Avian Biology 37: 431-435.

15. Rolshausen G, Segelbacher G, Hobson KA, Schaefer HM (2009) A recent migratory divide facilitates the contemporary evolution of reproductive isolation and phenotypic divergence in sympatry. Current Biology 19: 1-5.

16. Hobson KA, Lormée H, Van Wilgenburg SL, Wassenaar LI, Boutin JM (2009) Stable isotopes $(\delta \mathrm{D})$ delineate the origins and migratory connectivity of harvested animals: the case of European woodpigeons. Journal of Applied Ecology 46: 572-581.

17. Chamberlain CP, Blum JD, Holmes RT, Feng X, Sherry TW, et al. (1997) The use of isotope tracers for identifying populations of migratory birds Oecologia 109: 132-141.

18. Wunder M, Norris DR (2008) Analysis and design for isotope-based studies of migratory animals. In: Hobson KA, Wassenaar LI, eds. Tracking animal migration with stable isotopes Academic Press, San Diego, CA. pp 107-128.

19. Wunder M, Hobson KA, Kelly J, Marra P, Wassenaar LI, et al. (2009) Does a lack of design and repeatability compromise scientific criticism? A response to Smith et al. Auk 126: 922-926.

20. Bowen GJ, Wassenaar LI, Hobson KA (2005) Application of stable hydrogen and oxygen isotopes to wildlife forensic investigations at global scales. Oecologia 143: $337-348$

21. Popa-Lissenau AG, Sörgel K, Luckner A, Wassenaar LI, Ibáñez C, et al. (2012) A triple-isotope approach to predict breeding origins of European bats. PLOS One 7(1): e30388. doi:10.1371/journal.pone.0030388.

22. Rocque DA, Ben-David M, Barry RP, Winker K (2006) Assioning birds to wintering and breeding grounds using stable isotopes: lessons from two feather generations among three intercontinental migrants. Journal of Ornithology 147: 395-404.

23. Rocque DA, Ben-David M, Barry RP, Winker K (2009) Wheatear molt and assignment tests: ongoing lessons in using stable isotopes to infer origins. Journal of Ornithology 150: 931-934. 
24. Farmer A, Cade BS, Torres-Dowdall J (2008) Fundamental limits to the accuracy of deuterium isotopes for identifying the spatial origin of migratory animals. Oecologia 158: 183-192.

25. Smith AD, Lott CA, Smith JP, Donohue KC, Wittenberg S, et al. (2009) Deuterium measurements of raptor feathers: Does a lack of reproducibility compromise geographic assignment? Auk 126: 41-46.

26. Hobson KA (2011) Isotopic Ornithology: a perspective. Journal of Ornithology 152: 49-66.

27. Martínez del Rio G, Wolf N, Carleton SA, Gannes LZ (2009) Isotopic ecology ten years after a call for more laboratory experiments. Biological Reviews 84: 91-111.

28. Greenwood JL, Dawson RD (2011) Correlates of deuterium enrichment in the feathers of adult American kestrels of known origin. Condor 113: 555-564.

29. Pietsch SJ, Hobson KA, Wassenaar LI, Tütken T (2011) Tracking cats: Problems with placing feline carnivores on $\delta^{18} \mathrm{O}, \delta \mathrm{D}$ isoscapes. PLoS ONE 6(9): e24601. doi:10.1371/journal.pone.0024601.

30. Lott CA, Smith JP (2006) A geographic-information-system approach to estimating the origin of migratory raptors in North America using hydrogen stable isotope ratios in feathers. Auk 123: 822-835.

31. Clark RG, Hobson KA, Wassenaar LI (2006) Geographic variation in the isotopic $\left(\delta \mathrm{D}, \delta^{13} \mathrm{C}, \delta^{15} \mathrm{~N}, \delta^{34} \mathrm{~S}\right)$ composition of feathers and claws from lesser scaup and northern pintail: implications for studies of migratory connectivity. Canadian Journal of Zoology 84: 1395-1401.

32. DeSante DF, Burton KM, Saracco JF, Walker BL (1995) Productivity indices and survival-rate estimates from MAPS, a continent-wide programme of constant-effort mist-netting in North America. Journal of Applied Statistics 22: 935-947.

33. Pyle P (1997) Identification guide to North American birds Slate Creek Press, Bolinas CA.

34. Wassenaar LI, Hobson KA (2003) Comparative equilibration and online technique for determination of non-exchangeable hydrogen of keratins for use in animal migration studies. Isotopes in Environment and Health Studies 39: 1-7.

35. Poole A, ed. (2005) The Birds of North America Online: http://bna.birds. cornell.edu/BNA/. Cornell Laboratory of Ornithology, Ithaca, NY.

36. Van Wilgenburg SL (2011) IsoMAP job 5986, Isoscapes Modeling, Analysis and Prediction (version 1.0). The IsoMAP Projecthttp://isomap.org.

37. Mitchell TD, Jones PD (2005) An improved method of constructing a database of monthly climate observations and associated high resolution grids. International Journal of Climatology 25: 693-712.
38. Burnham KP, Anderson DR (2002) Multimodel selection and multimodel inference: A practical information theoretic approach Springer-Verlag, New York, USA.

39. Hobson KA, Greenberg R, Van Wilgenburg SL, Mettke-Hoffman C (2010) Migratory connectivity in the Rusty Blackbird (Euphagus carolinus) in North America: isotopic evidence from feathers of historical and contemporary specimens. Condor 112: 778-788.

40. Royle JA, Rubenstein DR (2004) The role of species abundance in determining the breeding origins of migratory birds using stable isotopes. Ecological Applications 14: 1780-1788.

41. Van Wilgenburg SL, Hobson KA, Brewster KR, Welker JM (2012) Assessing dispersal in a threatened migratory birds using stable-hydrogen isotope analysis of feathers $(\delta \mathrm{D})$. Endangered Species Research 16: 17-29.

42. Van Wilgenburg SL, Hobson KA (2011) Combining feather stable isotope $(\delta \mathrm{D})$ and band recovery data to improve probabilistic assignment of migratory birds to origin. Ecological Applications 21: 1340-1351.

43. Hobson KA, Wassenaar LI, Bayne EM (2004) Using isotopic variance to detect long-distance dispersal and philopatry in birds: An example with Ovenbirds and American Redstarts. Condor 106: 732-743.

44. Fraser KC (2010) Seasonal migration and diet use a Neotropical community of birds and bats. Ph.D. Thesis. University of New Brunswick, Fredericton, Canada.

45. Powell LA, Hobson KA (2006) Enriched feather hydrogen isotope values for Wood Thrushes sampled in Georgia, USA, during the breeding season: implications for quantifying dispersal. Canadian Journal of Zoology 84: 1331-1338.

46. Ellsworth PZ, Williams DG (2007) Hydrogen isotope fractionation during water uptake by woody xerophytes. Plant Soil 291: 93-107.

47. Birchall J, O'Connell TC, Heaton THE, Hedges REM (2005) Hydrogen isotope ratios in animal body protein reflect trophic level. Journal of Animal Ecology 74: 877-881.

48. Clark ID, Fritz P (1997) Environmental Isotopes in Hydrogeology Lewis Publishers, New York.

49. Bump JK, Fox-Dobbs K, Bada JL, Koch PL, Peterson RO, et al. (2007) Stable isotopes, ecological integration and environmental change: wolves record atmospheric carbon isotope trend better than tree rings. Proceedings of the Royal Society B 274: 2471-2480. 